Revue québécoise de linguistique

\title{
On the Application of Wh Movement and Inversion in Code-Switching Sentences
}

\section{Ellen Woolford}

Volume 14, numéro 1, 1984

Grammaires en contact

URI : https://id.erudit.org/iderudit/602528ar

DOI : https://doi.org/10.7202/602528ar

Aller au sommaire du numéro

Éditeur(s)

Université du Québec à Montréal

ISSN

0710-0167 (imprimé)

1705-4591 (numérique)

Découvrir la revue

Citer cet article

Woolford, E. (1984). On the Application of Wh Movement and Inversion in Code-Switching Sentences. Revue québécoise de linguistique, 14(1), 77-85.

https://doi.org/10.7202/602528ar
Résumé de l'article

Cet article étudie les contraintes sur l'application de mouvement Wh et d'inversion du sujet dans les phrases contenant un changement de code. L'auteur montre que ces contraintes découlent entièrement des principes de la grammaire tels qu'ils sont énoncés dans la théorie de Gouvernement et Liage (Chomsky 1981). d'utilisation que vous pouvez consulter en ligne. 


\title{
ON THE APPLICATION OF WH MOVEMENT AND INVERSION IN CODE-SWITCHING SENTENCES*
}

\author{
Ellen Woolford
}

\section{Introduction}

Although clause boundaries are generally a preferred site for codeswitching, there are several classes of constructions in which there are constraints on switching at S or S'. Building on the model of Woolford (1983), ${ }^{1}$ this paper focuses on two such constructions in Spanish-English code-switching: embedded questions and long distance Wh extraction of

1. Under the model presented in Woolford (1983), code-switching sentences are generated by means of a cooperation of the two monolingual grammars involved. Phrase structure rules appear to be drawn freely from either language to generate constituent structures, but the lexicons of each language only have access to the terminal nodes created by rules from their own language. Thus, while terminal nodes created by rules common to both language may be filled freely from the lexicon of either language, terminal nodes created by a rule unique to one language must be filled by the lexicon of that language. The fact that this model uses only the rules of the two monolingual grammars (and does not posit any sort of third code-switching grammar) is consistent with the fact that, fluent bilinguals do not have to learn to the syntactic constraints on code-switching. They already know how to code-switch properly as a result of thier knowledge of the grammars of the languages involved.

It is important to note that this model applies to only code-switching by bilinguals with native fluency in both languages. Bilinguals who learned one of their languages in adulthood (after the critical age of about twelve) use a very different model of code-switching. For a discussion of the systematic differences between the judgements of native versus secondlanguage bilinguals, and some speculation on the nature of the model of second-language bilinguals, see Woolford (1984).

* This research was supported by a fellowship from the Center For Cognitive Science at the University of Texas under a grant from the Sloan foundation. I would like to thank Raymundo Galindo for his assistance in gathering the data for this paper. 
subjects. New data is presented on the switching possibilities in these constructions and tentative hypotheses are put forth as to the causes of these constraints. The explanation of these constraints involves the conditions for the application of the transformations of Wh movement and inversion to hybrid sentences. It is shown that the pattern of grammatical and ungrammatical code-switching versions of these constructions follow entirely from principles of grammar in the Government Binding framework that apply to monolingual sentences and no additional stipulations unique to code-switching have to be added.

\section{Embedded Questions}

Although both Spanish and English allow embedded questions with roughly the same base structure, Spanish differs from English in requiring inversion of subject and verb. This feature is retained in the dialect of South Texas Spanish from which the data on code-switching in this paper is drawn.

(1) Do you know what that guy bought?

(2) a. *Sabes tú que ese vato compró?

b. Sabes tú que compró ese vato?

Code-switching is possible at a number of points in this construction. The data in (3) and (4) show grammatical switches at the S' boundary of the embedded clause. ${ }^{2}$

(3) Do you know que compró ese vato?

(4) Sabes tú what that guy bought?

Switching at the $\mathrm{S}$ boundary, however, creates the ungrammatical combinations in (5) and (6).

(5) *Do you know what compró ese vato?

(6) *Sabes tú que that guy bought?

2. Switching is also possible between the subject and the verb of the lower clause, as in (i) et (ii) below.

(i) Sabes tú que compró that guy?

(ii) Do you know what ese vato bought?

Data such as this falsifies early hypotheses such as the equivalence constraint of as Poplack (1979) which predict the impossibility of code-switching whenever the word order of the two languages differs before and after the proposed switch point. 
It is not the case that there is a general constraint against switching at this point because the example in (7) with inversion suppressed in the Spanish portion is grammatical. ${ }^{3}$

(7) Do you know what ese vato compró?

In contrast, however, we cannot improve example (6) by introducing inversion into the English portion of the sentence in any fashion, nor can we substitute a Spanish complementizer in (7).

(8) a. *Sabes tú que bought that guy?

b. *Sabes tú que did that guy buy?

(9) *Do you know que ese vato compró?

What is the explanation for this pattern of grammatical and ungrammatical switches? The bulk of the data discussed in Woolford (1983) was accounted for in terms of differences in the phrase structure rules and subcategorization requirements of the two languages. The above data cannot be accounted for in these terms, however since the key difference between the grammars in this case involves a transformation. Thus we must now address the question of what requirements must be met in a hybrid sentence for a transformation unique to one of the grammars to apply.

The simplest answer to this question is the one which is consistent with the central notion of this model - that nothing more than the rules of the two monolingual grammars can be used to explain constraints on codeswitching. The requirements for the application of a transformation to a hybrid sentence must be identical to the requirements for the application of that transformation to a monolingual sentence. With respect to the Spanish inversion transformation we are presently considering, it is generally agreed that some feature of the Spanish verbal/inflection system allows the possibility of this type of inversion (cf. Rizzi 1982) and that some feature of thematic Wh words such as que obligatorily triggers it (cf. Torrego 1984).

3. The grammaticality of (7) in contrast to the ungrammaticality of (5) falsifies the early view of code-switching as a complete switch in mid-string from speaking one language to speaking the other. If this were so, we would expect to find the Spanish portion of this sentence in its ordinary inverted order as in (5). We would have no explanation of why it is grammatical only with a word order that deviates from the normal Spanish construction.

Because the very name "code-switching" derives from this inaccurate view, many scholars prefer to refer to the phenomenon under discussion as "code-mixing". 
This information about the differences between English and Spanish will account for almost all of the data considered thus far. Taking the examples in reverse order, we see that (9) is ungrammatical because que requires inversion, but the lower clause is not inverted. Que also requires inversion in (8) and here the English clause appears to be inverted, but the ungrammaticality of these examples indicates that the nature of the English verbal/inflection system is incompatible with the particular type of inversion that is required. Example (7) is grammatical because the English Wh word does not trigger inversion. The Spanish portion of the sentence can occur in uninverted order because although the Spanish verbal/inflectional system allows inversion, it does not require it. Even in monolingual sentences, inversion does not occur without the presence of Wh in COMP. As in (9), que requires obligatory inversion in (6), but no inversion has occurred. The opposite situation holds in (5) where there is no que to trigger inversion, but it has occurred anyway. Finally, (3) and (4) are grammatical since que co-occurs with an inverted Spanish clause and what co-occurs with an uninverted English clause.

Although this account works well, it leaves several questions unanswered. Within recent work in syntax in Government-Binding theory, the device of triggers for transformations is no longer considered to be a possible grammatical device. All transformations are assumed to be optional and what causes particular transformations to appear to be prohibited in one case, but apply obligatorily in another is now traced to other factors in the sentence. A transformation will appear to be obligatory if the sentence in its untransformed state violates a principle of grammar. For example, if a noun phrase is not be assigned case in its base position, the sentence will be judged ungrammatical unless that NP moves somewhere where it will get case. Thus, it is insufficient merely to say that que triggers inversion and what does not. We want to know precisely what property of que and other Spanish thematic Wh words causes an embedded sentence to be judged ungrammatical unless inversion has occurred. Likewise, we want to know what property of what is incompatible with such inversion. There are already various hypotheses as to what property of the Spanish verbal/inflection system allows this type of inversion. One possibility, under the assumption that the inversion rule involves the movement of the $\mathrm{NP}$, rather than the verb, is that the Spanish verb or inflection provides a suitable environment (in terms of government or binding requirements) for the moved element and its trace. 
It is clear that a final account of this code-switching data must wait until the details of these differences between Spanish and English grammar have been clarified. Nevertheless, code-switching data such as this can be a valuable aid in this endeavor, however, since code-switching allows us to separate out isolate the effect of different elements in sentences in a manner that is often not possible in monolingual sentences. We have already gained valuable information from the small amount of data considered here that allows us to reject certain potential hypotheses. For example, it is clear from the grammaticality of example (6b) that the property of que which causes it to trigger inversion must be some property that is not shared with the English Wh word what because what does not trigger, or even allow the inversion. Similarly, we know from this same example that a Wh trace can be properly bound and governed, etc., within a Spanish clause even without inversion and thus we cannot attribute the necessity for inversion in examples such as (2) to such a source.

\section{That-trace Phenomena}

The examples in (10) and (11) demonstrate two well-known differences between the grammars of Spanish and English:

(i) In English, the that complementizer is only optionally present on the surface in this construction whereas in Spanish the comparable complementizer que is obligatorily overt.

(ii) English bars long-distance Wh extraction from subject position when the adjacent complementizer is present, whereas Spanish does not.

(10) a. *Who do you think that will come?

b. Who do you think will come?

c. Who do you think that John saw?

d. Who do you think John saw?

(11) a. Quién piensas tú que va a venir?

b. *Quién piensas tú va a venir?

c. A quién piensas tú que Juan vio?

d. *A quién piensas tú Juan vio?

In light of these differences, is not surprising that code-switching is not entirely free in such constructions. Both versions in which a switch occurs at the $\mathrm{S}$ boundary and COMP is filled are ungrammatical. 
(12) *Who do you think that va a venir?

(13) *Quién piensas tú que will come?

However, both versions are considerably improved if the complementizer is omitted.

(14) ?Who do you think va a venir?

(15) ?Quién piensas tú will come?

To understand this data we must first understand the underlying differences between the grammars of these two languages that account for the fact that Spanish appears to violate the 'that-trace' constraint whereas English obeys it. Within the Government-Binding framework of Chomsky (1981), the standard view of the cause of the ungrammaticality of (10a) is that the presence of the complementizer blocks proper government of the trace in subject position. The Spanish version in (11a) is grammatical, despite the fact that the COMP position is filled, because inversion has occurred in the lower sentence and the Wh trace is actually in a post-verbal position where it is properly governed by the verb. (Under this hypothesis, the inversion rule does not leave a trace in subject position which is in need of proper government.)

Code-switching versions of this construction should therefore be judged ungrammatical whenever the trace of Wh movement is not properly governed. In (12), the presence of that in COMP blocks proper government of the subject of the lower clause and the ungrammaticality of this example indicates that inversion is blocked in the lower clause despite the fact that it is Spanish. This is what we would expect under Torrego's (1984) hypothesis that when long-distance Wh movement occurs, inversion is triggered cyclically by the presence of the Spanish Wh word in COMP, as we saw in section one. In (12), the Wh word which passes through COMP is English so we would not expect inversion to be possible. In (13), the situation is reversed. The Wh word which passes through COMP is Spanish and must trigger inversion, but the lower clause is English and cannot undergo inversion for the reasons discussed in section one.

In contrast to these examples, the code-switching versions of this construction in (14) and (15) lack a filled COMP to block proper government of the Wh trace in subject position without the necessity of inversion. What has to be explained, however, is why (15) does not require inversion since the Wh word that moves is Spanish. As Torrego has demonstrated, Spanish 
(like Italian, but unlike English) allows a Wh to skip one intermediate COMP and move directly up to the matrix COMP in constructions such as (15). If this is possible here, then inversion would not necessarily be triggered in the lower clause and a grammatical sentence is possible. This raises an additional question: how are the bounding nodes determined in codeswitching sentences when the two languages involved set them differently? It is interesting to note that while the judgements of all of the other examples in this section remain firm under repeated retesting, the judgement of (15) varies from quite good to quite bad. Is this sentence judged with English bounding nodes one time and Spanish another? At this point in our knowledge, we can only speculate.

One might think that the analysis of the ungrammaticality of (12) and (13) presented above predicts that (12) should be grammatical if we substitute quién for who (because quién would trigger the required inversion in the Spanish lower clause as it passed through COMP) and likewise that (13) should be significantly improved by the substitution of who for quién (for that would remove the obligation for inversion in the English lower clause). We see by the examples in (16) and (17) that these combinations are not grammatical.

(16) *Quién do you think que va a venir?

(17) *Who piensas tú que will come?

The problem in these examples is that although conditions may be improved in the lower clause by matching the language of the Wh word with that clause, new problems are created in the matrix clause by the mismatch introduced there. The constraint against switching between a matrix Wh word in COMP and the remainder of the sentence has already been noted in Peñalosa (1980) and Woolford (1983). The reason for this constraint appears to be that although both languages require inversion when the matrix COMP contains a Wh word, there are actually two different rules involved. When the details of these rules are more clearly understood, we should be able to construct a more precise account of the ungrammaticality of (16) and (17).

There is data of another type, however, that supports the notion that the language of the Wh word which passes through COMP determines whether or not inversion occurs in the lower clause. Viewed in the traditional terms of a switch from one grammar to another, the ungrammaticality of examples such as (18) below is extremely puzzling. The switch 
occurs at a major constituent boundary common to both languages (and a switch at this point was perfectly grammatical in example (3)) and both portions of the sentence are consistent with the word order of the source language.

(18) *Who do you think que va a venir?

In contrast, under the current view, the ungrammaticality of such examples follows in a straightforward manner from the fact that inversion could not occur in the lower clause due to the fact that the Wh word which passes through COMP is English, rather than Spanish. Without inversion, the Wh trace sits in subject position where its proper government is blocked by the presence of que in COMP.

\section{Conclusion}

In this paper we have addressed the question of how transformations apply to the hybrid constituent structures created during code-switching. The data investigated here concerns the possibilities for Spanish-English code-switching within constructions involving Wh movement and inversion. The constraints on switching within these constructions can be accounted for solely in terms of the independently motivated rules and principles of the two monolingual grammars developed within Government Binding theory in work such as Chomsky (1981), Rizzi (1982), and Torrego (1984). No external code-switching constaints are necessary, even to account for the application of transformations that are unique to one of the languages involved. Thus we can conclude that the transformations of the two languages apply freely to code-switching sentences, just as they apply freely to monolingual sentences, and any improper consequences of this free application of transformations get filtered out by other principles of grammar such as the requirement that empty nodes be properly bound under ECP.

\section{Ellen Woolford}

\section{Linguistics}

The Pennsylvania State University 


\section{Références}

CHOMSKY, Noam (1981), Lectures on Government and Binding Foris, Dordrecht.

PEÑALOSA, Fernando (1980), Chicano Sociolinguistics, Newbury House, Rowley, Massachusetts.

POPLACK, Shana (1979), "Sometimes I Start a Sentence in Spanish y Termino en Español: Toward a Typology of Code-Switching", Working Papers in the Center for Puerto Rican Studies, vol. 4, CUNY, New York.

RIZZI, Luigi (1982), "Wh Movement, Negation and the Pro-Drop Parameter", in Issues in Italian Syntax, Foris, Dordrecht.

TORREGO, Esther (1984), "On Inversion in Spanish and Some of Its Effects", Linguistic Inquiry 15, 103-153.

WOOLFORD, Ellen (1983), "Bilingual Code-Switching and Syntactic Theory", Linguistic Inquiry 14, 520-536.

WOOLFORD, Ellen (1984), "Systematic Differences in the Code-Switching Judgements of Balanced versus Second-Language Bilinguals", paper presented at the VIII Symposium of Spanish and Portuguese Bilingualism, University of Massachusetts, Amherst. 